INTERNATIONAL JOURNAL OF MULTIDISCIPLINARY RESEARCH AND ANALYSIS

ISSN(print): 2643-9840, ISSN(online): 2643-9875

Volume 03 Issue 12 December 2020

DOI: 10.47191/ijmra/v3-i12-09, Impact Factor: 5.522

Page No.- 321-323

\title{
Pedagogical Conditions for the Development of Artistic Perception in Children of the Fifth Year of Life in the Process of Familiarization with Works of Fine Art
}

\author{
Nargiza Fatkhullaevna Abdunazarova ${ }^{1}$, Makhzuna Tursunovna Khamdamova ${ }^{2}$, \\ Nafisa Shavkatovna Abdullaeva ${ }^{3}$, Bahora Akromovna Khodjayorova ${ }^{4}$ \\ ${ }^{1}$ Candidate of Pedagogical Sciences, Associate Professor Institute of Retraining and Advanced Training of Pre-School Education \\ Institutions, Tashkent, Uzbekistan \\ ${ }^{2}$ Independent researcher Institute of retraining and advanced training of managers and specialists of preschool educational \\ institutions, Tashkent, Uzbekistan \\ ${ }^{3}$ Doctor of Philosophy in Pedagogical Sciences (PhD) Institute of retraining and improvement of professional skill of managers \\ and specialists of preschool educational institutions, Tashkent, Uzbekistan \\ ${ }^{4} \mathrm{PhD}$ student Samarkand State University, Samarkand, Uzbekistan
}

ABSTRACT: The article considers the problem of the development of artistic perception in children of the fifth year of life. The paper substantiates the possibility and necessity of developing artistic perception in preschool age, the features of using works of fine art in the development of artistic perception of preschool children, the willingness of a teacher to develop artistic perception of pupils, as well as the relationship of directly educational activities with the independent creativity of children.

KEYWORDS: Artistic perception, language of fine art, works of fine art, willingness of a teacher, development of artistic perception, artistic perception of children.

\section{INTRODUCTION}

The basis of any artistic creation is artistic perception. It enables a person to enter the world of artistic culture, allows you to create new artwork based on your own worldview. In the scientific literature, artistic perception is defined as the formation in the consciousness of the person of an emotionally colored, associatively multifaceted, rhythmically ordered, image of the world, spiritually meaningful and objectified in the material of the language of art, the image of the world in the process of a complex multi-level dialogue of the artist with the outside world and an imaginary viewer; and the viewer (reader, listener) - with himself, the author of a work of art, with culture.

\section{METHODOLOGY}

The development of artistic perception is possible already in preschool age. In the educational field "Artistic and Aesthetic Development" of the "Childhood" program for children of the middle group, the task of developing artistic perception is formulated as follows:

- to intensify interest in works of folk and professional art and to form an experience in the perception of works of art of va rious types and genres, to contribute to the development of some means of expressiveness of fine art;

- develop artistic perception, the ability to carefully carefully examine works of art and objects of the world; correlate what he saw with his own experience;

- to form figurative ideas about objects and phenomena of the world and on their basis to develop the ability to depict simple objects and phenomena in their own activities [1, p. 148].

The most successful artistic perception is developing in the field of fine art, as it is a holistic way of reflecting the world, an organic holistic worldview of a preschooler 


\section{Pedagogical Conditions for the Development of Artistic Perception in Children of the Fifth Year of Life in the Process of Familiarization with Works of Fine Art}

\section{RESULTS AND DISCUSSION}

In addition, according to research by teachers and psychologists, the development of artistic perception occurs only on the basis of the experience of one's own creativity, and the creation of images is the kind of creativity in which a preschool child is most active. Therefore, preschool age is sensitive for the development of artistic perception.

The development of the ability to perceive the child is considered in the scientific works of many teachers, such as T.V. Kalinina, A.A. Melik - Pashaev, N.V. Frost, T.N. Tomina et al. [2-4; 6]. Researchers also emphasize the need to preserve and develop the emotionality of the child's direct perception..

According to some researchers (A.A. Melik - Pashaev, N.V. Moroz, N.I. Smakovskaya, T.N. Tomina, etc.), the development of the artistic perception of a preschool child is facilitated by familiarization with works of fine art [3-6]. However, in practice, when acquainting children with works of fine art, teachers pay more attention to the content component of the picture, while the expressive means used by the artist do not always become the object of perception. Therefore, our study was devoted to the search for pedagogical conditions for the development of artistic perception in children of middle preschool age in the process of familiarization with works of fine art.

Currently, there is an increase in the social role of the personality of the teacher as a carrier of artistic culture and the importance of the artistic education of teachers. This problem was reflected in the research of N. I. Smakovskaya [5]. The author considers the readiness of the teacher to implement artistic and aesthetic upbringing and education as the most important condition in the development of the artistic perception of preschool children. The teacher should understand the importance and necessity of introducing preschoolers to works of fine art, master the technique of familiarizing children with works of art and provide favorable conditions for solving the problems of artistic and aesthetic development of pupils.

In the studies of teachers, special attention is paid to such a pedagogical condition as the organization of an artistic and aesthetic environment in the educational space, which is enriched by the integration of educational fields. Therefore, the work on the development of children's artistic perception must begin with the creation of an artistic environment, with the organization of mini-galleries. Mini galleries can be dedicated to the work of famous artists, as well as to the work of preschoolers. This will allow children to feel the value of their own efforts in creating drawings, their significance for others and will serve as an incentive for further creativity.

In the group room of the kindergarten, a place should be determined for placing portraits of famous artists, books on fine art, art encyclopedias, reproductions of paintings. Children should have free access to these materials. It is advisable to periodically update both the content of mini-galleries and the contents of bookshelves. For example, you can follow the principle of seasonality: in winter, offer children to familiarize themselves with reproductions of artists depicting the different conditions of winter. It is good if the teacher, when selecting reproductions, draws attention to various techniques used by artists to create the painting, which will allow preschoolers to see the possibility of a variety of images of various objects, phenomena of the world. And also, after daily observations of weather conditions and changes in nature, it would be useful to find in the reproductions of artists a reflection of similar or similar in content environmental states, weather.

Most programs and techniques emphasize the need to master the language of art as an expressive language. Along with mastering the drawing technique, attention is focused on the development of the expressive possibilities of the elements of the language of art by children and the development of the ability to dialogically communicate with a work of art, and the ability to comprehend an idea on the basis of understanding the form.

Therefore, in the process of organizing visual activity, it is necessary to draw the attention of children to the expressive possibilities of the language of visual art: color options (warm - cold, light - dark); line options (straight, wavy, broken); hatching features ("direct", "radial"); features of the spot, different in shape, weight, color; rhythm features (color, lines, spots, stroke). It is also important to familiarize children with the techniques of working with art materials: gouache ("stretching", brushwork); watercolors ("stretching", "raw"); colored pencils and wax crayons (hatching with a change in pressure on the pencil (crayon) and the direction of the stroke). A positive result in the development of color as a language of fine art gives experimentation with paints. Children can be invited to independently obtain a new color or its shade by mixing colors.

When the teacher directly organizes educational activities, it is necessary to take into account the principle of the gradual development of individual elements of the language of fine art. Children's understanding of the essence of the language of art as a means of communication is carried out as a result of the teacher's explanations in combination with the child's own visual activity, on the basis of self-understanding of the created images.

In the process of perception of paintings by children, it is necessary to promote awareness of their own experiences as the main content of the work; their awareness of the form, including its rhythmic structure as a source of experiences; awareness of the 


\section{Pedagogical Conditions for the Development of Artistic Perception in Children of the Fifth Year of Life in the Process of Familiarization with Works of Fine Art}

process of perception as a multi-level dialogue, the starting point of which is one's own experiences, and the means of dialogue is the study of this experience in the process of experimenting with form.

So, for example, in the process of acquaintance with the painting, children can be offered to mentally become a participant in the plot of the picture, so that try to look around already from the perspective of a participant in specific events. It is important that the teacher by his example demonstrates the emotional attitude to the perceived picture, which will cause the effect of "emotional infection" in children and will contribute to the activation of children's perception.

It is advisable to bring children to the evaluation of the characters depicted in the picture. Effectively use the conversation with issues of a problematic nature. Questions will lead children to understanding the true face of the characters depicted, their motives.

In the conditions of independent visual activity, it is important to assist children in mastering the language of visual arts. To this end, you can organize experimented with paints: obtaining new shades of color, mixed colors, etc.

In the afternoon, it is recommended that children conduct educational exercises such as "Who is who?", "Think of a landscape", "Pick a palette", "Where whose contour", etc. Children will fix in an exciting form for them. So, for example, the game exercise "Who is who?" Will contribute to the development of synesthesia, association. Children are invited to listen to the story of an evil wizard who turned characters (cooks, ballerinas and military men) into figures (square, rectangle and triangle), then children are invited to conjure figures - find representatives of these professions, explain the choice. Any answers and explanations of children that are not even consistent with logic are accepted. It is important that children try to relate, reason, beat.

\section{CONCLUSION}

Thus, the success in the development of artistic perception in children of middle preschool age in the process of familiarization with works of fine art can be ensured by the implementation of the following pedagogical conditions: the willingness of teachers of preschool education to develop artistic perception among preschool children; providing an aesthetic developmental environment in a preschool educational institution and in the family; the relationship of directly educational activities with experimentation and independent creativity of children.

\section{REFERENCES}

1) Childhood: An approximate educational program of preschool education [Text] / T.I. Babaeva [et al.]. - St. Petersburg: Childhood Press, 2014 .- 352 p.

2) Kalinina T.V. Pedagogical technology for the development of artistic perception of children 6-7 years old based on a combination of elements of the language of fine art / T.V. Kalinina [Electronic resource]. - Access mode: http://nauka-pedagogika.com

3) Melik - Pashaev A.A. An artist in every child. Objectives and methods of art education [Text] / A.A. Melik - Pashaev. - M.: Education, 2008 .- 175 p.

4) Frost N.V. Perception of art as the basis for the formation of the artistic culture of a person / N.V. Frost [Electronic resource] / Access mode: http://academicon.ru

5) Smakovskaya N.I. The development of artistic perception among students of teacher training college in the context of the interaction of arts / R.I. Smakovskaya [Electronic resource]. - Access mode: http://nauka-pedagogika.com

6) Tomina T.N. The development of artistic perception in children of preschool age when getting acquainted with painting works / T.N. Tomina [Electronic resource]. - Access mode: http: //festival.1sep 